\title{
Efeitos de Valores Numéricos Menores e Maiores sobre o Desempenho em Atividades Matemáticas Elementares
}

\author{
Rafaella Donini ${ }^{1}$ \\ Pontificia Universidade Católica de São Paulo, São Paulo, SP, Brasil \\ Nilza Micheletto \\ Faculdade de Psicologia da Pontificia Universidade Católica de São Paulo, \\ São Paulo, SP, Brasil
}

\begin{abstract}
Resumo
O ensino de matemática pode ser planejado a partir dos comportamentos que já estão estabelecidos no repertório do aluno, o que remete à importância de caracterizar esse repertório e identificar possíveis controles já estabelecidos. Analisar se valores numéricos menores - entre um e três - e valores numéricos maiores - entre sete e nove - produziriam diferenças em uma amostra de desempenho de três crianças em atividades que testaram relações comportamentais entre estímulos e respostas componentes de repertórios matemáticos elementares foi objetivo desta pesquisa. Dimensões irrelevantes (espacial, tamanho e forma dos elementos) dos conjuntos de elementos foram variadas e manipuladas nas atividades, buscando identificar se as respostas estariam sendo controladas pela dimensão relevante - número. Para isto foram planejadas, com três crianças com idades de 6 a 9 anos, atividades que avaliavam relações entre estímulos e respostas relativas aos conceitos de igualdade, mais, menos, maior, menor, sequência crescente e sequência decrescente. Foram atividades de emparelhamento de identidade ou arbitrário, que envolviam relações entre estímulos modelo e comparação (figuras, conjunto de figuras, algarismos, instruções orais) e respostas de selecionar estímulos comparação, de construir conjuntos ou sequencias; e também atividades que envolviam respostas de tatear número de figuras e respostas textuais diante de algarismos. De maneira geral, os resultados indicaram maior número de acertos em tentativas nas quais valores entre um e três foram empregados do que em tentativas nas quais valores entre sete a nove foram usados. Tais resultados apoiam a sugestão de que o ensino de relações matemáticas seja iniciado com valores numéricos menores.
\end{abstract}

Palavras-chave: Comportamento matemático, habilidades numéricas, avaliação de repertório.

\section{Effects of Lower and Higher Numeric Values on Elementary Mathematical Activities Performance}

\footnotetext{
Abstract

The teaching of mathematics can be designed from behaviors already established on student's repertoire, and that refers to the importance to characterize the repertoire and identify possible controls already

Endereço para correspondência: Rua Vicente Leporace, 1204, Apto. 91, São Paulo, SP, Brasil 04619-033. Fone: (11) 5041-6194. E-mail: nimicheletto@uol.com.br

Trabalho relacionado a este artigo foi apresentado na forma de painel na XXXV Reunião Anual da Sociedade Brasileira de Psicologia, em Curitiba em out. de 2005.

Este trabalho é parte da dissertação de mestrado do primeiro autor, "Identificando comportamentos prérequisitos para o ensino de adição e subtração", sob orientação da segunda autora, no Programa de Psicologia Experimental: Análise do Comportamento da Pontifícia Universidade Católica de São Paulo (PUC-SP). O primeiro autor recebeu auxilio da Coordenação de Aperfeiçoamento de Pessoal de Nível Superior (CAPES), em forma de bolsa de mestrado.
} 
established. The objective of this research was to analyze if smaller numerical values - between one and three - and larger numerical values - between seven and nine - would make differences on a sample of performance of three children on tasks those tested behavioral relations between stimuli and responses components of mathematical elementary repertoires. Irrelevant dimensions (spatial arrangement, size and shape of the elements) of the sets of elements were varied and manipulated on tasks, searching to identify if the responses would be controlled by relevant dimension - number. For that, tasks were planned and applied with three children age 6-9 years. Those activities evaluated relations between stimuli and responses concerning to the concepts of equality, more, less, larger, smaller, crescent sequence, and decreasing sequence. The tasks were identity or arbitrary matching-to-sample and involved relations between sample stimulus and comparison stimuli (pictures, sets of pictures, numerals, oral instructions) and responses of selecting comparison stimuli, constructing sets or sequences. Other activities involved responses of tacting number of pictures and textual responses in the presence of numerals. In general, the results indicated higher number of correct responses on trials that employed values between one and three than on trials that used values between seven and nine. These results support the suggestion of begin the teaching of mathematical relations with smaller numerical values.

Keywords: Mathematical behavior, numerical abilities, repertoire assessment.

\section{Efectos de Valores Numéricos Menores y Mayores sobre el Rendimiento en Actividades Matemáticas Elementales}

\section{Resumen}

El enseño de matemática puede ser planeado a partir de comportamientos que ya están establecidos en el repertorio del estudiante, lo que se refiere a la importancia de caracterizar ese repertorio y identificar controles posiblemente ya establecidos. Fue el intento de esa investigación analizar si valores numéricos menores - entre uno y tres - y valores numéricos mayores - entre siete y nueve - producirían diferencias en una muestra de rendimiento de tres niños en actividades que testaron relaciones comportamentales entre estímulos y respuestas que componen repertorios matemáticos elementares. Dimensiones irrelevantes de los conjuntos de elementos (espacial, tamaño y forma de los elementos) fueron variadas y manipuladas en las actividades, buscando identificar si las respuestas estarían siendo controladas por la dimensión relevante - número. Fueron planeadas y realizadas actividades con tres niños en edad de 6-9 años, que evaluaban relaciones entre estímulos y respuestas relativas a los conceptos de igualdad, más, menos, mayor, menor, secuencia creciente y secuencia decreciente. Fueron actividades de igualación de la muestra por igualdad o arbitrarios, que envolvían relaciones entre estímulos modelo y comparación (figuras, conjunto de figuras, guarismos, instrucciones orales) y respuestas de selección de estímulos, de construir conjuntos o secuencias, respuestas de tactear número de figuras y respuestas textuales delante guarismos. Por lo general, los resultados indicaron mayor número de aciertos en tentativas que empleaban valores entre uno y tres qué en tentativas que usaron valores entre siete y nueve. Tales resultados apoyan la sugerencia de que el enseño de relaciones matemáticas sea iniciado con valores numéricos menores.

Palabras clave: Comportamiento matemático, habilidades numéricas, repertorio de evaluación.

Alguns pesquisadores têm se dedicado ao estudo do ensino da matemática, seja construindo sequências hierárquicas de comportamentos componentes de um repertório matemático introdutório (Resnick, Wang, \& Kaplan, 1973;
Silva, 1999; Teixeira, 2002), seja empregando o paradigma de equivalência de estímulos (Araújo \& Ferreira, 2008; de León, 1998; Gast, VanBiervliet, \& Spradlin, 1979; Green, 1993; Kahhale, 1993; Monteiro \& Medeiros, 2002; Prado, 2001; 
Prado \& de Rose, 1999; Rossit, 2004; Teixeira, 2002; Williams, 2000).

Nesses trabalhos, são descritas relações comportamentais entre estímulos e respostas que compõem o conceito de número - números falados, números de elementos, algarismos, contagem de elementos, respostas textuais evocadas por algarismos; formação de subconjuntos; ordenação de números falados, conjuntos e/ou de algarismos; palavras escritas/nomes de números; e são descritas relações de igualdade, desigualdade, "mais", "menos", "maior que" e "menor que" entre valores numéricos.

Resnick et al. (1973) propuseram que o ensino de relações para os números de um a cinco antecedesse o ensino de relações para os números de seis a dez; essa divisão baseou-se em considerações da prática educacional e, segundo os autores, poderia maximizar a experiência de sucesso das crianças. De modo semelhante, Teixeira (2002) dividiu seu programa de ensino em duas partes, sendo que a primeira abordou valores numéricos de um a cinco, e a segunda parte focou o ensino de valores de seis a dez. Segundo Prado e Carmo (2004), um fator que contribui para o ensino das relações entre estímulos e respostas envolvendo os valores de um a quatro é a possibilidade que temos de identificar quantidades de um a quatro elementos sem precisarmos emitir respostas sucessivas de enumeração, o que os autores chamaram de subtização.

A análise de atividades pré-requisito para aquisição de repertório matemático tem sido conduzida em trabalhos cujos resultados têm favorecido o planejamento de condições de ensino. Monteiro e Medeiros (2002) destacam a importância da contagem na instalação do repertório matemático. Eles propuseram um procedimento no qual foram ensinadas a dois grupos de crianças pré-escolares relações entre algarismo e número de elementos, algarismo e palavra impressa, número falado e algarismo, e a apenas um desses grupos foi ensinada a contagem oral de elementos: as crianças submetidas previamente ao ensino da contagem apresentaram, em testes de relações emergentes e em testes de generalização, um número consideravelmente maior de acertos do que as crianças que não foram expostas ao ensino da contagem.

Cada valor numérico é um exemplo de conceito que, segundo de Rose (1993), é definido pelas relações arbitrárias estabelecidas diretamente entre os estímulos que compõem o conceito. Tomando como exemplo o valor numérico três, observarmos que a palavra falada "três", conjuntos compostos por três elementos, o algarismo 3 e a palavra escrita "três" são estímulos que podem vir a compor o conceito "três". O valor numérico ou número é a dimensão relevante; outras dimensões dos estímulos que compõem a classe são irrelevantes, tais como a forma dos elementos que compõem cada conjunto, o tamanho e a disposição espacial dos elementos.

Prado e de Rose (1999), concebendo o conceito de número como uma rede de relações, analisaram o desempenho de crianças em uma serie de tarefas consideradas pré-requisito para aprendizagens matemáticas mais complexas. Organizaram as tarefas de emparelhamento com o modelo em três passos. No primeiro e segundo passos, foram usados como estímulos desenhos de objetos supostamente conhecidos $\mathrm{e}$, no terceiro, formas geométricas. No primeiro passo, a disposição dos desenhos obedecia a arranjos ordenados (disposição simétrica, ou seja, o tamanho, a forma e a disposição espacial dos elementos eram mantidos constantes, variando apenas a dimensão quantidade); no segundo, eram desordenados (disposição assimétrica, ou seja, a disposição espacial era variada). Foram avaliadas, no primeiro passo, tarefas na seguinte ordem: nomeação de numerais, contagem de figuras que formavam um conjunto, seleção de numerais a partir de números ditados, pareamento conjunto-numerais e numerais-conjunto. No segundo passo, as mesmas tarefas, exceto a primeira, foram realizadas, porém com arranjos assimétricos. No passo 3, variou-se a forma e o tamanho dos elementos do conjunto, nas tarefas do passo anterior. Segundo os autores, "não houve diferenças marcantes do desempenho dos sujeitos em função da simetria ou assimetria dos conjuntos" (p. 232). A comparação dos acertos nos três passos indicou que a dimensão espacial 
foi a dimensão irrelevante que mais interferiu na diminuição do número de acertos, nas crianças com idades entre três e quatro anos. Quando todas as dimensões irrelevantes variavam só a contagem permitia escolha correta. Os participantes que não tinham esta habilidade tiveram maior número de erros.

Uma dimensão irrelevante que sempre é apresentada com a dimensão relevante pode se tornar a dimensão que controla a resposta do aluno, muitas vezes em detrimento da dimensão relevante. Sendo assim, para verificar se as respostas do aluno são de fato controladas pela dimensão relevante - o valor numérico, o professor precisa realizar testes em que a dimensão relevante é dissociada das dimensões irrelevantes que previamente foram apresentadas com ela (de Rose, 2004, 2005). Em outras palavras, faz-se necessário planejar atividades em que a dimensão relevante seja sempre a mesma e em que as dimensões irrelevantes dos estímulos sejam variadas.

O presente estudo teve como objetivo analisar se valores numéricos menores - entre um e três - e valores numéricos maiores - entre sete e nove - produziriam diferenças em uma amostra de desempenho de crianças expostas a atividades em que: (a) o valor numérico foi a dimensão relevante e (b) testaram relações comportamentais entre estímulos e respostas componentes dos conceitos de igualdade, mais, menos, maior, menor, sequência crescente e sequência decrescente. O maior número de acertos em tentativas nas quais os valores numéricos fossem menores, em comparação ao número de acertos em tentativas com valores numéricos maiores, poderia apoiar a sugestão de que o ensino de relações para valores menores fosse implementado antes do ensino de relações para valores maiores. Dimensões irrelevantes dos conjuntos de elementos (disposição espacial, tamanho e forma dos elementos) foram variadas ou manipuladas nas atividades, buscando identificar se as respostas dos participantes estariam sendo controladas efetivamente pela dimensão relevante - número - ou se uma ou mais dimensões irrelevantes estariam exercendo controle.

\section{Método}

\section{Participantes}

Três crianças participaram do estudo: A., com seis anos de idade, estava frequentando uma instituição de educação infantil, no início do estudo; L., com sete anos de idade, estava na primeira série do ensino fundamental; e S., com nove anos de idade, estava cursando a terceira série. As crianças A. e L. foram selecionadas pelas diretoras da instituição de educação infantil e do centro de atividades. A participante $\mathrm{S}$. foi selecionada devido às dificuldades no processo de ensino-aprendizagem de comportamentos acadêmicos, descritas por seus professores. A participação de todos foi autorizada pelos pais ou responsáveis por meio de Termo e consentimento Livre e Esclarecido.

\section{Local}

A pesquisa foi realizada na instituição de educação infantil frequentada por A., e no centro de atividades frequentado por L. e S., no período em que essas crianças não estavam na escola. As sessões foram realizadas na biblioteca que a instituição de educação infantil e o centro de atividades têm em comum.

O período final da coleta com a participante A. foi realizado em sua casa, uma vez que ela deixou de frequentar a instituição de educação infantil.

\section{Material}

As atividades matemáticas planejadas foram impressas em folhas e agrupadas em diferentes "cadernos". Cada folha correspondia a uma tentativa.

Os estímulos que compuseram as atividades foram impressos em folhas de papel A4. Podiam estar impressos: uma ou mais figuras, um ou mais algarismos, um ou mais sinais matemáticos. Também foram utilizados estímulos impressos avulsos: figuras, conjuntos de figuras e algarismos.

Foram propostas atividades de escolha de acordo com o modelo (MS) ou resposta constru- 
ída (CMS) em que o participante formava conjuntos ou sequências. Elas poderiam envolver como estímulo-modelo ou estímulo-comparação figuras, conjunto de figuras, algarismos, ou palavras faladas. Poderia também ser estímulo-modelo palavras faladas que eram apresentadas sozinhas ou acompanhando outros estímulos. Foram também propostas atividades em que o participante deveria tatear. Na Figura 1, estão representados alguns exemplos de diferentes tentativas que envolveram escolha de acordo com o modelo. Foram utilizados como estímulos: numerais, sinais $(=,<,>)$, figuras, sequências e conjuntos de figuras, que podiam ser apresentadas de forma a variar dimensões irrelevantes dos conjuntos de elementos (disposição espacial, tamanho e forma dos elementos). O estímulo-modelo era apresentado na parte superior da folha e os estímulos-comparação na inferior da folha. Nas atividades de emparelhamento de resposta construída (formar um subconjunto e ordenar estímulos em sequências crescente e decrescente), eram apresentados cartões, de aproximadamente $8,5 \times 8,5 \mathrm{~cm}$, com os estímulos comparação, cada estímulo em um cartão.

\section{Procedimento}

O procedimento envolveu duas fases: preliminar e de comparações numéricas.

Na Fase Preliminar, foram planejadas atividades para testar comparações entre figuras e conjuntos de figuras que envolveram os conceitos de igualdade, mais, menos, maior, menor, sequência crescente e sequência decrescente, sem o uso de valores numéricos. Foram aplicadas três tentativas para cada atividade. $\mathrm{Na}$ Tabela 1, são apresentadas as 13 relações entre estímulo-modelo e estímulo-comparação e as respostas envolvidas em cada uma delas, na sequência em que foram apresentadas para os participantes.

Na Fase de Comparações Numéricas, foram testadas várias atividades, cada atividade correspondeu a uma relação comportamental entre estímulos e respostas componentes dos conceitos de igualdade, mais, menos, maior, menor, sequência crescente e decrescente. $\mathrm{O}$ conceito de igual foi testado em 29 relações (apresenta- das nas Tabelas 2 e 3); os conceitos de mais (Tabela 4) e menos (Tabela 5) foram testados em oito relações cada; os conceitos de maior (Tabela 6) e menos (Tabela 7) foram testados em 11 relações cada; e os conceitos de sequencia crescente (Tabela 8) e decrescente foram testados em 3 relações cada um. Foram planejadas três tentativas para cada atividade: uma em que o valor numérico do estímulo antecedente foi um, ou dois, ou três; outra tentativa em que o valor numérico do estímulo antecedente foi ou quatro, ou cinco, ou seis - e outra tentativa em que o valor numérico do estímulo antecedente foi ou seis, ou sete, ou nove.

Em ambas as fases, foram apresentadas atividades de emparelhamento que tiveram um estímulo-modelo e dois ou mais estímulos-comparação. Na maioria das atividades foram utilizados dois ou três estímulos-comparação; as exceções foram as seguintes: na atividade de emparelhamento de resposta construída entre figuras, doze estímulos-comparação foram usados; na atividade de emparelhamento de identidade entre algarismos, nas atividades de formar subconjunto com número de figuras igual ou correspondente ao estímulo-modelo, nas atividades que envolveram a ordenação de figuras, conjuntos de figuras e algarismos em sequência crescente e em sequência decrescente, foram empregados nove estímulos-comparação.

As atividades consistiram em: emparelhamento de identidade e emparelhamento arbitrário, que envolveram respostas de selecionar um estímulo-comparação; emparelhamento de resposta construída, que envolveram formar um subconjunto e ordenar estímulos em sequências crescente e decrescente; atividades de tatear número de figuras e relação entre números de figuras; e atividades que envolveram resposta textual diante de um algarismo.

Os comportamentos exigidos nas atividades foram ordenados de acordo com seu nível de dificuldade e foram organizados a partir dos seguintes critérios: relações que tiveram, entre seus estímulos antecedentes, figuras antes das que tiveram conjuntos de figuras (como pode ser observado na Figura 1, a primeira tentativa envolveu figuras e a quarta tentativa era constituída 


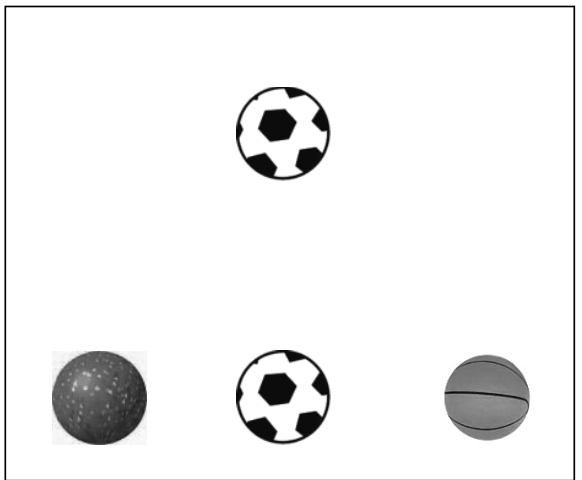

Escolher, entre figuras, a igual ao modelo

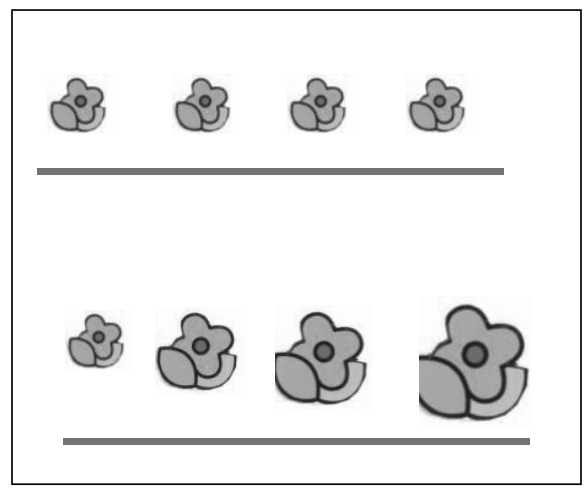

Escolher, entre sequencias, a que as figuras são dispostas da menor para a maior

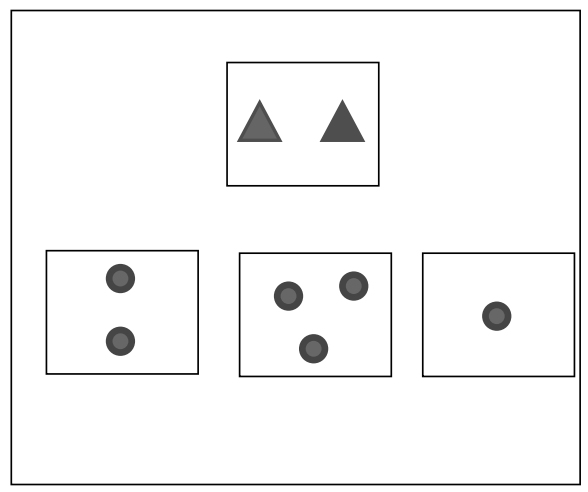

Escolher entre conjuntos, com variação $n a$ forma e disposição, o de número igual

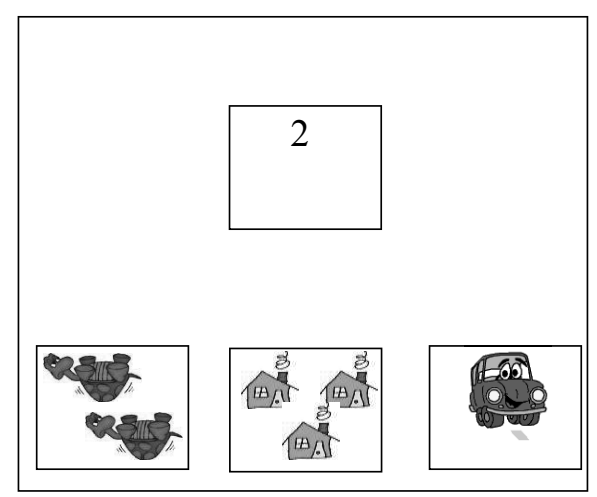

Escolher, entre conjuntos com números diferentes de figuras, o que tem mais figuras que o algarismo

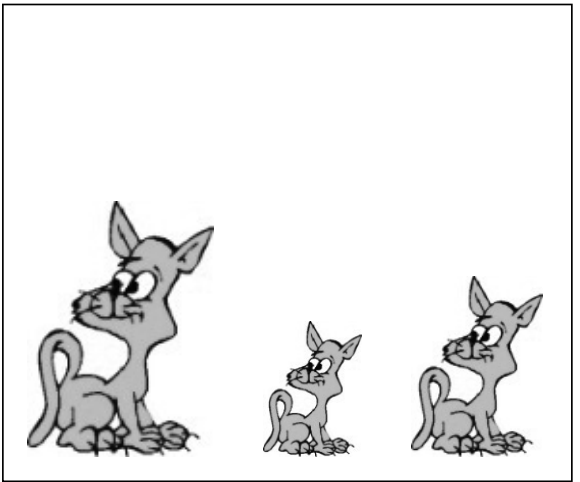

Escolher, entre figuras, a maior

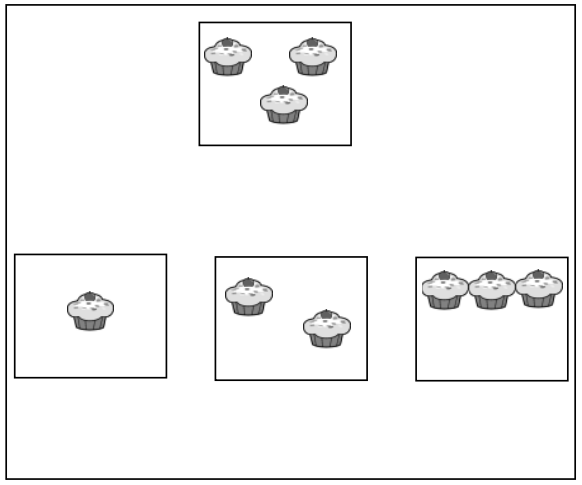

Escolher, entre conjuntos com variação na disposição espacial das figuras, o de número igual

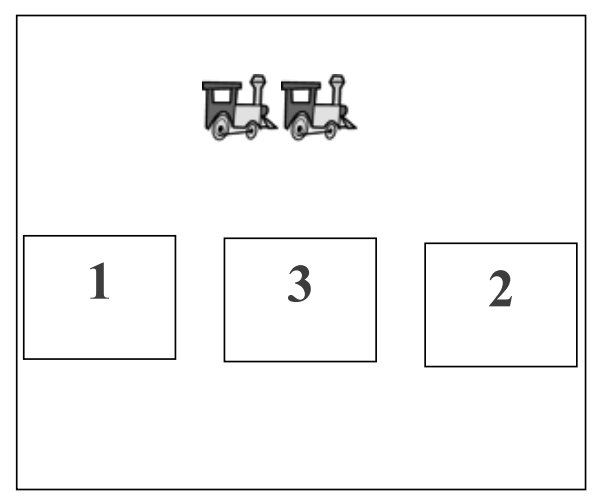

Escolher, entre algarismos, o algarismo cujo valor é menor do que o número de figuras

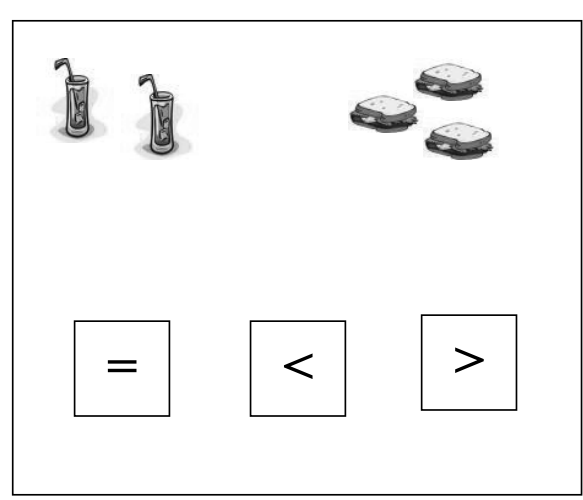

Escolher entre os sinais, o que relaciona dois conjuntos com números diferentes de figuras

Figura 1. Exemplos de tentativas em que foram utilizados como estímulos figuras, conjunto e sequências de figuras, algarismo e sinais. 
de conjuntos de figuras). Estas, por sua vez, foram introduzidas antes de relações que tiveram, entre seus estímulos antecedentes, algarismos (Figura 1, sexta tentativa), e sinais matemáticos. Relações que implicaram a emissão de uma cadeia de respostas foram precedidas por relações que envolveram cada uma destas respostas separadamente. Por exemplo, resposta na tentativa quatro da Figura 1 - escolher, entre conjuntos, o igual ao modelo - envolveu previamente respostas de comparar conjuntos, que foram precedidas de respostas de contar quantos elementos (bolos) tinham em cada um dos conjuntos apresentados como estímulos comparação e contar o número de elementos do conjunto apresentado como modelo. Já a resposta na tentativa um - escolher entre figuras a igual ao modelo - não envolvia respostas de contar, apenas comparar.

As atividades propostas para algumas relações foram planejadas de forma que o controle por diferentes dimensões de estímulos apresentados pudesse ser identificado; ou seja, em relações em que a dimensão relevante que deveria controlar as respostas foi o número de figuras de cada conjunto, dimensões irrelevantes das figuras componentes dos conjuntos foram manipuladas, tais como a forma, a disposição espacial e o tamanho das figuras.

As atividades foram organizadas em unidades. Na definição da ordem em que as unidades foram apresentadas, considerou-se o grau de complexidade dos comportamentos. As unidades foram assim sequenciadas:

1. Relacionar números falados, quantidades e numerais correspondentes;

2. Fazer comparações entre quantidades de figuras;

3. Fazer comparação entre quantidades e numerais e entre numerais;

4. Fazer comparações entre quantidades, usando sinais gráficos;

5. Formar subconjuntos. Nas Tabelas 2 a 8, são apresentadas as relações entre estímulo-modelo e estímulo-comparação e as respostas envolvidas em cada uma das atividades das unidades (indicadas, na Tabela, com número que antecedem a descrição das relações), na sequência em que foram apresentadas para os participantes.
Em cada tentativa das atividades, foi solicitado que a criança, como resposta de observação, passasse seu dedo embaixo dos estímulos apresentados e, a seguir, a pesquisadora instruiu oralmente a criança em relação a o que deveria ser feito.

Para cada atividade, foi fornecida uma instrução composta por estímulos auditivos, sendo que um deles foi a expressão falada correspondente ao conceito envolvido na atividade: a palavra falada "igual" (para o conceito de igualdade), "mais", "menos", "maior", "menor", “aumentando de tamanho" ou "Comece colocando o menor e vá continuando, até chegar no maior" (para o conceito de sequencia crescente), "diminuindo de tamanho" ou "Comece colocando o maior e vá continuando, até chegar no menor" (para o conceito de sequência decrescente).

Não foram liberadas consequências contingentes às respostas emitidas pela criança nas tarefas apresentadas, entretanto elogios da pesquisadora, pela participação na pesquisa ocorreram de forma não contingentes às respostas. No final de cada sessão, a criança poderia escolher uma guloseima ou um pequeno brinde.

As sessões foram feitas individualmente. A duração das sessões variou de acordo com a disponibilidade de cada criança, durando entre meia hora até uma hora e meia, uma vez por dia. Sendo assim o número de tentativas realizadas numa sessão variou em função do tempo que a criança tinha disponível e de seu ritmo. Como as atividades estavam ordenadas e organizadas em cadernos, cada sessão dava continuidade às atividades a partir da tentativa em que a sessão anterior foi encerrada. Em cada sessão, foi feita uma ou mais pausas, durante as quais o participante descansou e/ou brincou com brinquedos.

O período de coleta teve a duração de cerca de três meses.

Para avaliar o acordo entre pesquisadores, uma observadora participou de quatro sessões e registrou independentemente as respostas emitidas por uma criança. Foi feito um cálculo, dividindo-se o número de respostas da criança sobre as quais o registro da pesquisadora e o registro da observadora estavam de acordo pelo número total de respostas da criança observadas por ambas; o resultado foi multiplicado por 100 . O 
resultado final indica que a concordância foi de $97,51 \%$

\section{Resultados e Discussão}

Foram testadas várias relações comportamentais entre estímulos e respostas componentes dos conceitos de igualdade, mais, menos, maior, menor, sequência crescente e decrescente, com os participantes. Ao final da coleta de dados, cada participante havia completado um número diferente de atividades: A. realizou todas as atividades relacionadas aos conceitos de igualdade, mais, menos, maior, menor, sequência crescente, sequência decrescente (nestas atividades, foram avaliadas 86 diferentes relações, sendo cada uma delas testadas por meio de 3 tentativas); L. realizou as atividades relativas aos conceitos de igualdade, mais, menos, maior e menor (foram avaliadas 78 relações); e S. completou as atividades relacionadas à igual- dade, mais, menos, maior, menor e parte das atividades de sequência crescente (foram avaliadas 75 relações). As Tabelas de 1 a 8 apresentam estas relações testadas.

\section{Fase Preliminar}

Nessa fase, as atividades aplicadas envolveram as relações de igualdade, mais, menos, maior, menor, sequência crescente e sequência decrescente entre estímulos auditivos, figuras e conjuntos de figuras.

$\mathrm{Na}$ Tabela 1, estão representados as atividades que compõem a Fase Preliminar, com os estímulos antecedentes e respostas de cada atividade, o conceito envolvido na atividade e o desempenho dos participantes A., L. e S nas atividades nas quais foram testadas relações de igualdade, maior, menor, mais, menos, sequência crescente e sequência decrescente entre estímulos auditivos, figuras e/ou conjuntos de figuras.

Tabela 1

Desempenho dos Participantes A., L. e S. em Atividades nas quais são Testadas Relações de Igualdade, Maior, Menor, Mais, Menos, Sequência Crescente e Sequência Decrescente entre Estímulos Auditivos Figuras e/ou Conjuntos de Figuras. Foram Três Tentativas de Cada Relação

\begin{tabular}{|c|c|c|c|c|}
\hline \multirow{2}{*}{ Relação entre estímulo-modelo - estímulos-comparação e respostas } & \multirow{2}{*}{ Conceito } & \multicolumn{3}{|c|}{ Tentativas } \\
\hline & & A & $\mathrm{L}$ & $\mathrm{S}$ \\
\hline $\begin{array}{l}\text { Figura e Palavra falada “igual” - Escolher, entre três figuras, aquela que é igual à } \\
\text { figura/estímulo-modelo }\end{array}$ & Igualdade & 3 & 3 & 3 \\
\hline Palavra falada "maior" - Escolher, entre três figuras, aquela que é maior de tamanho & Maior & 3 & 3 & 3 \\
\hline Palavra falada "menor" - Escolher, entre três figuras, aquela que é menor de tamanho & Menor & 0 & 2 & 0 \\
\hline Palavra falada "mais" - Escolher, entre três figuras, a figura que é a mais alta & Mais & 3 & 3 & 3 \\
\hline Palavra falada "menos" - Escolher, entre três figuras, a figura que é a menos alta & Menos & 0 & 0 & 0 \\
\hline $\begin{array}{l}\text { Palavra falada "aumentando" - Escolher, entre duas sequências, aquela em que } \\
\text { figuras de tamanhos diferentes são dispostas da menor para a maior }\end{array}$ & $\begin{array}{l}\text { Sequência } \\
\text { crescente }\end{array}$ & 3 & 3 & 3 \\
\hline $\begin{array}{l}\text { Palavra falada "diminuindo" - Escolher, entre duas sequências, aquela em que figuras } \\
\text { de tamanhos diferentes são dispostas da maior para a menor }\end{array}$ & $\begin{array}{l}\text { Sequência } \\
\text { decrescente }\end{array}$ & 3 & 0 & 3 \\
\hline $\begin{array}{l}\text { Palavra falada "igual” e Conjunto composto por figuras idênticas entre si - Escolher, } \\
\text { entre três conjuntos, aquele é igual ao conjunto/estímulo-modelo }\end{array}$ & Igualdade & 3 & 2 & 3 \\
\hline $\begin{array}{l}\text { Palavra falada "igual" e Conjunto composto por figuras diferentes entre si - Escolher, } \\
\text { entre três conjuntos, aquele é igual ao conjunto/estímulo-modelo }\end{array}$ & Igualdade & 3 & 3 & 3 \\
\hline $\begin{array}{l}\text { Palavra falada "igual” e Conjunto de figuras - Formar, a partir de figuras espalhadas, } \\
\text { um conjunto igual ao conjunto/estímulo-modelo }\end{array}$ & Igualdade & 3 & 3 & \\
\hline $\begin{array}{l}\text { Palavra falada "igual" e sequência de figuras - Escolher, entre três sequências, aquela } \\
\text { que igual à sequência/modelo - com variação na disposição espacial }\end{array}$ & Igualdade & & 0 & \\
\hline
\end{tabular}


Instrução relativa à sequência crescente e Figuras de tamanhos diferentes - Ordenar as figuras em ordem crescente, de acordo com o tamanho

Instrução relativa à sequência decrescente e Figuras de tamanhos diferentes - Ordenar as figuras em ordem decrescente, de acordo com o tamanho

Total de acertos

Total de relações sem erros
Sequência 0

crescente

Sequência 0

decrescente $\begin{array}{ll}0 & 0\end{array}$

$\begin{array}{lll}0 & 0 & 0\end{array}$
Na maior parte das tentativas das atividades relacionadas ao conceito de igual, as crianças emitiram respostas corretas; com exceção de um erro de L. na atividade de escolher o conjunto igual ao conjunto apresentado como estímulo-modelo, os outros erros ocorreram para todos os participantes somente na atividade de escolher, entre três sequências, aquela que igual à sequência/modelo - com variação na disposição espacial; a variação na disposição espacial possivelmente contribuiu para os erros.

Nas atividades em que se solicitou que cada criança escolhesse, entre três figuras, aquela que fosse a menor e a menos alta, nenhum participante escolher corretamente em todas as tentativas. Na atividade correspondente para o conceito de maior, as três crianças corretamente selecionaram a figura maior em cada tentativa. Por outro lado, na atividade em que o participante deveria escolher, entre três figuras, aquela que fosse "menos alta", as três crianças emitiram respostas incorretas em todas as tentativas. Tais erros podem decorrer do fato de, no dia-a-dia, as pessoas não falarem "menos alta", mas sim falarem "mais baixa".

De qualquer maneira, a dimensão altura foi aleatoriamente usada nas atividades para testar a relação entre a palavra falada "mais" e mais intensidade de uma dimensão específica de um estímulo visual (figura), e entre a palavra falada "menos" e menos intensidade de uma dimensão específica de um estímulo visual. Em estudos futuros, as relações envolvendo os conceitos de mais e de menos podem ser testadas usando outras dimensões específicas de estímulos, diferentes da altura. Semelhante procedimento poderá ser adotado para testar relações envolvendo os conceitos de maior e de menor, uma vez que na presente pesquisa foi utilizada apenas a dimensão específica tamanho.
Conforme é possível observar na Tabela 1, somente o participante L. emitiu respostas incorretas na atividade de escolher, entre duas sequências, aquela em que figuras de tamanhos diferentes foram dispostas da maior para a menor; em todas as tentativas, criança sistematicamente selecionou a sequência cujas figuras foram apresentadas no tamanho igual entre si. Na tarefa em que foi solicitado que a criança escolhesse a sequência de figuras dispostas da menor para a maior, L. acertou em todas as tentativas. Nas atividades em que cada criança foi solicitada a ordenar nove figuras de tamanhos diferentes em sequência crescente e em sequência decrescente, os três participantes não ordenaram corretamente a sequência completa de figuras em tentativa alguma. Essas atividades de resposta construída arbitrária apresentaram um grau de dificuldade maior do que aquele apresentado na atividade de resposta construída de identidade (Palavra falada "igual" e Conjunto composto por figuras idênticas entre si - Escolher, entre três conjuntos, aquele é igual ao conjunto/estímulo-modelo), na qual as crianças apresentaram respostas corretas.

Nessa presente pesquisa, relações envolvendo os conceitos de "antes" e "depois" não foram testadas. Em trabalhos posteriores, seria interessante introduzir atividades que testassem relações entre a palavra falada "antes" e outros estímulos - por exemplo: eventos que diferissem entre si na dimensão específica tempo, de maneira que o aluno seria instruído a responder diferencialmente ao evento que ocorreu antes do outro. Isto poderia ser feitos por meio de atividades de ordenação de cenas de uma história. Também poderão ser introduzidas atividades que testem relações entre a palavra falada "depois" e outros estímulos - por exemplo: eventos que ocorreram em momentos diferentes, sendo que a criança 
seria solicitada a escolher ou tatear qual evento ocorreu depois do outro.

\section{Fase de Comparações Numéricas}

Relações comportamentais componentes do conceito de igualdade entre os seguintes estímulos e respostas foram avaliadas: conjuntos de figuras, sendo que o número de figuras foi a dimensão relevante e foram variadas dimensões irrelevantes entre o conjunto/estímulo modelo e os conjuntos/estímulos-comparação; número falado e conjunto de figuras; algarismos iguais entre si; número falado e algarismo; algarismo e conjunto de figuras; conjuntos com número igual de figuras e o sinal de igualdade $(=)$; algarismos iguais entre si e o sinal de igualdade $(=)$; resposta textual de algarismo; resposta de tatear a igualdade do número de figuras em conjuntos; formar subconjunto composto por número igual de figuras ao número do conjunto/estímulo-modelo; formar subconjunto composto por número de figuras igual ou correspondente a um número falado; formar subconjunto composto por número igual ou correspondente a um algarismo; agrupar conjuntos que tenham número igual de figuras entre si.

Acertos nas atividades que testaram, com os três participantes, as 24 relações envolvidas no conceito de igual, relativas a diferentes unidades (indicadas com números que precedem a descrição das relações) são representados na Tabela 2. As cinco atividades às quais somente a participante A. foi exposta, no período final da pesquisa, são descritas na Tabela 3. A ordem em que as atividades foram apresentadas às crianças é representada na ordem em que elas são descritas na Tabela 2 e 3, sendo que a atividade descrita em uma linha precedeu a atividade descrita na linha seguinte. Cada atividade foi testada em três tentativas, uma em cada faixa de valor numérico avaliado (1 a 3, 4 a 6 e 7 a 9). São indicados nas Tabelas com X os acertos em cada uma destas tentativas

Tabela 2

Desempenho dos Participantes A., L. e S em Atividades das Unidades (indicadas com números) nas quais as Relações entre Estímulos e Respostas Envolvem a Igualdade entre os Estímulos, em Função de Valores Numéricos Empregados: Menores (variando-se entre um e três), Intermediários (entre quatro e seis) e Maiores (entre sete e nove). São Indicadas com X Tentativas Corretas Unidade. Relação entre estímulo-modelo - estímulos-
comparação e respostas

\section{1 a 3}

7 a 9

$\begin{array}{llllllllll}\text { A } & \text { L } & \text { S } & \text { A } & \text { L } & \text { S } & \text { A } & \text { L } & \text { S }\end{array}$

1. Conjunto de figuras - Escolher, entre três conjuntos, aquele que tem número igual de figuras - sem variação em dimensões irrelevantes entre os conjuntos

1. Conjunto de figuras - Escolher, entre três conjuntos, aquele que tem número igual de figuras - com variação na disposição espacial das figuras

1. Conjunto de figuras - Escolher, entre três conjuntos, aquele que tem número igual de figuras - com variação no tamanho das figuras

1. Conjunto de figuras - Escolher, entre três conjuntos, aquele que tem número igual de figuras - com variação no tamanho $e$ na disposição espacial das figuras

1. Conjunto de figuras - Escolher, entre três conjuntos, aquele que tem número igual de figuras - com variação na forma

X X

$\begin{array}{llll}X & X & X & X\end{array}$

$\mathrm{X}$

$\begin{array}{lll}X & X & X\end{array}$

$\mathrm{X}$

$\mathrm{X} \quad \mathrm{X}$

1. Conjunto de figuras - Escolher, entre três conjuntos, aquele que tem número igual de figuras - com variação na forma e na disposição espacial

$\begin{array}{lllllll}X & X & X & X & X & & X\end{array}$

$\begin{array}{lllllllll}X & X & X & X & X\end{array}$

$\begin{array}{llllllll}X & X & X & X & X & X & X\end{array}$

$\begin{array}{lllllllll}X & X & X & X & X & X & X & X\end{array}$ 
1. Conjunto de figuras - Escolher, entre três conjuntos, aquele que tem número igual de figuras - com variação na forma e no tamanho

1. Conjunto de figuras - Escolher, entre três conjuntos, aquele que tem número igual de figuras - com variação na forma, no tamanho e na disposição

1. Conjunto de figuras - Escolher, entre três conjuntos, aquele que tem número igual de figuras - com variação na forma

$\begin{array}{lllllllllllllll}X & X & X & X & X & X & X\end{array}$

1. Conjunto de figuras - Escolher, entre três conjuntos, aquele que tem número igual de figuras - com variação na forma e na disposição espacial

1. Conjunto de figuras - Escolher, entre três conjuntos, aquele que tem número igual de figuras - com variação na forma e no tamanho

$\mathrm{X} \quad \mathrm{X} \quad \mathrm{X}$

$\mathrm{X}$

X X

X X

X X X

$\mathrm{X} \quad \mathrm{X}$

$\begin{array}{lllll}X & X & X & X & X\end{array}$

1. Conjunto de figuras - Escolher, entre três conjuntos, aquele que tem número igual de figuras - com variação na forma, na disposição e no tamanho

1. Número falado - Escolher, entre três conjuntos, aquele com número correspondente de figuras ordenadas

1. Número falado - Escolher, entre três conjuntos, aquele com número correspondente de figuras desordenadas

1. Algarismo - Escolher, entre nove algarismos, aquele que é igual

1. Número falado - Escolher, entre três algarismos, aquele cujo valor é correspondente

1. Algarismo e conjunto com número igual de figuras Formar, a partir de figuras espalhadas, um subconjunto com número igual de figuras

1. Três conjuntos com números diferentes de figuras Escolher, entre os três algarismos, aquele que é correspondente a cada conjunto/número de figuras

2. Dois conjuntos com número igual de figuras - Tatear que os conjuntos têm número igual de figuras

2. Três conjuntos com número igual de figuras - Tatear que os conjuntos têm número igual de figuras

$\mathrm{X}$

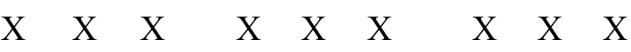

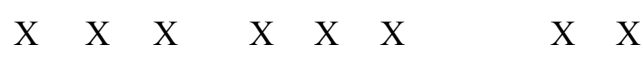

$\begin{array}{lllllll}X & X & X & X & X & X\end{array}$

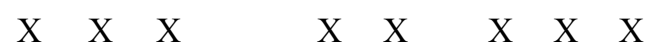

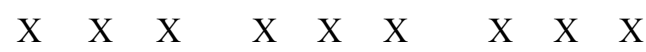

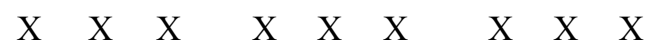

$\begin{array}{llllllll}X & X & X & X & X & X & X\end{array}$

$\begin{array}{llllllllllllll}X & X & X & X & X & X & X\end{array}$

$\begin{array}{llllll}X & X & X & X & X\end{array}$

X X X X

4. Dois conjuntos com número igual de figuras - Escolher, entre o sinal de igualdade e o sinal de desigualdade,

o sinal de igualdade

$\mathrm{X}$

X X

X X

4. Dois algarismos iguais - Escolher, entre o sinal de igualdade e o sinal de desigualdade, o sinal de igualdade

X X

X X

4. Dois conjuntos com número igual de figuras - Escolher, entre o sinal de igualdade, o sinal de maior e o sinal de menor o sinal de igualdade

$\mathrm{X}$

X X

$\mathrm{X}$

4. Dois algarismos iguais - Escolher, entre o sinal de igualdade, o sinal de maior e o sinal de menor, o sinal de igualdade

Total de acertos 
Tabela 3

Desempenho da Participante A. em Atividades das Unidades (indicadas com números) nas quais as Relações entre Estímulos e Respostas Envolvem a Igualdade entre os Estímulos, em Função de Valores Numéricos Empregados: Menores (variando-se entre um e três), Intermediários (entre quatro e seis) e Maiores (entre sete e nove). São Indicadas com $X$ Tentativas Corretas

Unidade. Relação entre estímulo-modelo - estímulos-comparação e respostas

1 a $3 \quad 4$ a $6 \quad 7$ a 9

5. Conjunto de figuras - Formar, a partir de figuras espalhadas, um subconjunto com número igual de figuras

X $\quad \mathrm{X} \quad \mathrm{X}$

5. Número falado - Formar, a partir de figuras espalhadas, um subconjunto com número correspondente de figuras

X X

5. Algarismo - Formar, a partir de figuras espalhadas, um subconjunto com número correspondente de figuras

1. Conjunto de figuras diferentes entre si - Escolher, entre três conjuntos, aquele com número igual de figuras

$\mathrm{X}$

X $\quad \mathrm{X} \quad \mathrm{X}$

$\mathrm{X}$

5. Conjuntos com números diferentes de figuras - Agrupar conjuntos que têm, entre si, número igual de figuras

Na Tabela 2 e 3, são especificados estímulos antecedentes e respostas envolvidas em cada atividade (é importante lembrar que, além daqueles estímulos antecedentes, outro estímulo apresentado foi a instrução oral); na coluna das Tabelas em que estão impressos os algarismos 1 a 3, é apresentado o desempenho de cada criança (A, L e S) na tentativa em que foram empregados valores variando entre um e três; na coluna em que estão impressos os algarismos 4 a 6 , desempenho na tentativa em que foram adotados valores variando entre quatro e seis; e, na coluna em que os algarismos 7 a 9 estão impressos, o desempenho na tentativa em que foram utilizados valores entre sete e nove. Nesta Fase de Comparações Numéricas foram realizadas três tentativas para cada relação, uma em cada faixa de valores numéricos ( 1 a 3, 4 a 6 e 7 a 9).

Como é possível observar na Tabela 2, todos os participantes emitiram um número consideravelmente maior de respostas corretas nas tentativas em que foram utilizados valores numéricos entre um e três do que nas tentativas em que foram usados valores entre sete e nove. Para a participante S., houve pouca diferença no número de acertos entre as tentativas nas quais foram empregados valores de um a três, quatro a seis, e sete a nove, mas o número de acertos em tentativas com valores menores e intermedi- ários foi maior do que em tentativas com valores maiores.

$\mathrm{Na}$ Tabela 3, nas atividades realizadas pela participante A, observa-se que a criança apresentou acertos em todas as tentativas dos valores de um a três; e, novamente, A. apresentou mais acertos nas tentativas dos valores de quatro a seis do que nas tentativas dos valores de sete a nove.

A partir da Tabela 2 e da Tabela 3, dados os acertos das crianças na maior parte das tentativas em que valores de um a três foram empregados, supõe-se que as respostas emitidas ficaram sob controle da dimensão relevante - número. Nas tentativas em que foram usados valores intermediários e maiores, o número exerceu controle sobre menos respostas.

A dimensão irrelevante tamanho e disposição especial das figuras presumivelmente exerceu controle inicialmente sobre respostas incorretas da participante A. em tentativas da atividade de escolher um conjunto com número igual de figuras ao número do conjunto/estímulo-modelo (erros passam a ocorrer com introdução de variações dessas dimensões). Para L. e S., não foram observados erros sistemáticos decorrentes da variação de uma dimensão irrelevante. Dimensões irrelevantes, tais como tamanho, disposição espacial das figuras podem ter exercido assistematicamente controle sobre respostas das crianças; 
outras respostas incorretas podem ter decorrido de erros de contagem. Respostas corretas podem ter passado a ocorrer em função da exposição dos participantes às tentativas, fortalecendo-se relações entre estímulos e respostas (como por exemplo, para o participante $\mathrm{S}$, na atividade em que são apresentados dois conjuntos com número igual de figuras, tatear que eles têm número igual de figuras; nas tentativas com valores de um a três ocorre erro que não mais ocorrem nas tentativas dos valores de quatro a seis e nas de valores de sete a nove).

O desempenho de cada participante nas atividades relativas ao conceito de mais pode ser observado na Tabela 4. Foram avaliadas, por meio de 24 tentativas, 8 relações entre os seguintes estímulos: palavra falada "mais" (componente da instrução em cada atividade), conjuntos de figuras, fileiras de figuras (dispostas verticalmente) e algarismos.

\section{Tabela 4}

Desempenho dos Participantes A., L. e S. em Atividades das Unidades (indicadas com números) nas quais as Relações entre Estímulos e Respostas Envolvem o Conceito de Mais entre os Estímulos, em Função de Valores Numéricos Empregados: Menores (variando-se entre um e três), Intermediários (entre quatro e seis) e Maiores (entre sete e nove). São Indicadas com X Tentativas Corretas

Unidade. Relação entre estímulo-modelo 1 a 3 4 a 6 7 a 9 estímulos-comparação e respostas

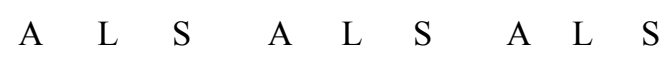

2. Palavra falada "mais" - Escolher, entre dois conjuntos com números diferentes de figuras, aquele que tem mais figuras

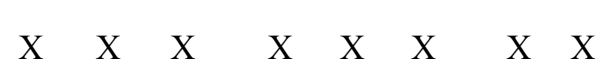

2. Palavra falada "mais" - Escolher, entre duas fileiras com números diferentes de figuras, aquela que tem mais - com variação na disposição espacial das figuras

$\begin{array}{llll}\mathrm{X} & \mathrm{X} & \mathrm{X}\end{array}$

2. Palavra falada "mais" - Escolher, entre três conjuntos com números diferentes de figuras, aquele que tem mais figuras

$\begin{array}{llllllllll}\text { X } & \text { X } & & \text { X } & \text { X } & \text { X } & \text { X } & & \\ & & & & & & & & \\ \text { X } & \text { X } & \text { X } & \text { X } & \text { X } & \text { X } & & \text { X } & \text { X }\end{array}$

2. Palavra falada "mais" - Escolher, entre três fileiras com números diferentes de figuras, aquela que tem mais - com variação na disposição espacial das figuras

3. Palavra falada "mais" - Escolher, entre um conjunto de figuras e um algarismo que não correspondem entre si, qual deles equivale a mais elementos

3. Palavra falada "mais" - Escolher, entre dois algarismos diferentes, o algarismo que indica mais elementos

3. Palavra falada "mais" - Escolher, entre três algarismos diferentes, o algarismo que indica mais elementos

3. Palavra falada "mais" e Algarismo - Escolher, entre três conjuntos com números diferentes de figuras, aquele que tem mais figuras do que o algarismo/modelo

\begin{tabular}{llllllllllll}
\hline Total de acertos & 8 & 8 & 5 & 5 & 7 & 6 & 3 & 7 & 2 \\
\hline
\end{tabular}

Todos os participantes emitiram mais respostas corretas em tentativas dos valores de um a três do que em tentativas dos valores de sete a nove. Os participantes A. e L. apresentaram acertos em todas as oito tentativas em que foram usados valores entre um e três, a participante $\mathrm{S}$. emitiu respostas incorretas em três das oito tentativas. Para o participante L., foi pequena a diferença no número de acertos em tentativas nas quais foram empregados os valores um a três, em comparação com as tentativas em que foram empregados valores maiores (diferença de apenas 
um acerto). A participante S. apresentou apenas um acerto a mais nas tentativas dos valores de quatro a seis do nas tentativas dos valores um a três. No conceito de mais para S e para A os valores numéricos maiores geraram menos acertos.

Na Tabela 5, são especificados os estímulos antecedentes e as respostas envolvidas nas ati- vidades relativas ao conceito de menos, assim como o desempenho de cada participante nas mesmas. Foram avaliadas, por meio de 24 tentativas, oito relações entre: palavra falada "menos" (presente na instrução de cada atividade), conjuntos de figuras, fileiras de figuras e algarismos.

\section{Tabela 5}

Desempenho dos Participantes A., L. e S. em Atividades das Unidades (indicadas com números) nas quais as Relações entre Estímulos e Respostas Envolvem o Conceito de Menos entre os Estímulos, em Função de Valores Numéricos Empregados: Menores (variando-se entre um e três), Intermediários (entre quatro e seis) e Maiores (entre sete e nove). São Indicadas com X Tentativas Corretas

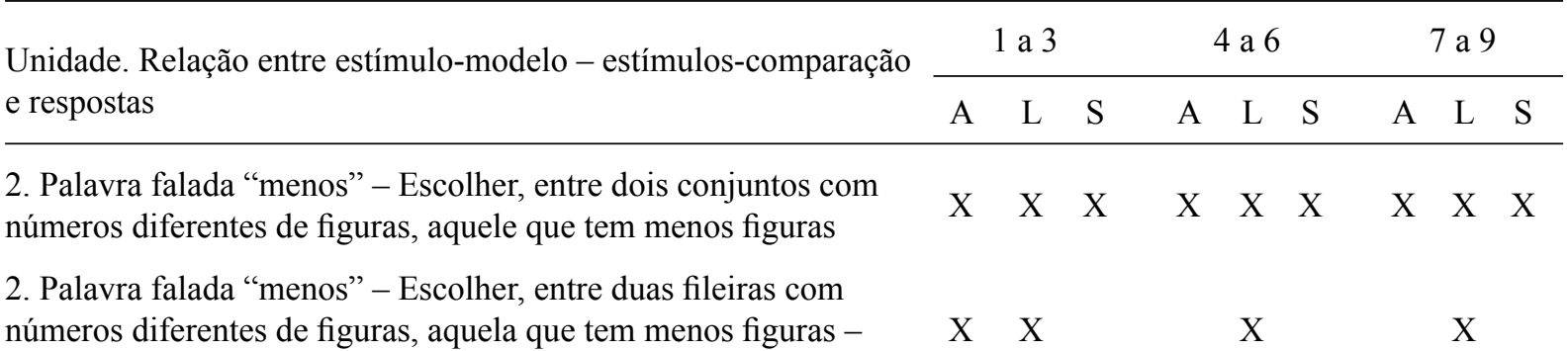
com variação na disposição espacial das figuras

2. Palavra falada "menos" - Escolher, entre três conjuntos com números diferentes de figuras, aquele que tem menos figuras

$\begin{array}{llllll}X & X & X & X & X & X\end{array}$

2. Palavra falada "menos" - Escolher, entre três fileiras com números diferentes de figuras, aquela que tem menos figuras - $\quad \mathrm{X} \quad \mathrm{X}$ com variação na disposição espacial das figuras

3. Palavra falada "menos" - Escolher, entre um conjunto de

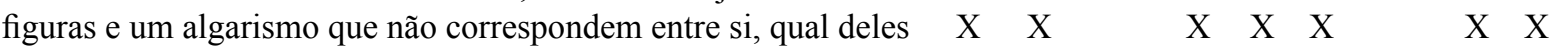
equivale a menos elementos

3. Palavra falada "menos" - Escolher, entre dois algarismos diferentes, o algarismo que indica menos elementos

$X \quad X \quad X \quad X \quad X$

3. Palavra falada "menos" - Escolher, entre três algarismos diferentes, o algarismo que indica menos elementos

$\begin{array}{lllll}X & X & X & X & X\end{array}$

3. Palavra falada "menos" e Algarismo - Escolher, entre três conjuntos com números diferentes de figuras, aquele que tem menos figuras do que o algarismo/modelo

Total de acertos

$\begin{array}{lllllllll}7 & 7 & 3 & 4 & 4 & 6 & 4 & 4 & 2\end{array}$

Os participantes A. e L. emitiram mais respostas corretas (sete das oito) em tentativas nas quais foram usados valores numéricos de um a três do que em tentativas nas quais os valores de quatro a seis e os valores de sete a nove (quatro das oito tentativas) foram empregados. A participante S. apresentou mais acertos nas tentativas em que os valores entre quatro e seis foram empregados do que nas tentativas em que valores inferiores e valores superiores foram usados; em tentativas que adotaram os valores de um a três, a criança apresentou apenas um acerto a mais em comparação ao número de acertos apresentados naquelas tentativas em que os valores de sete a nove foram adotados. Parece que S. respondeu sob controle de uma dimensão irrelevante em atividades em que isto é manipulado - a disposição espacial das figuras (na fileira com menos 
figuras, elas foram impressas com espaçamento maior entre si, gerando uma fileira mais comprida, enquanto que, na fileira com mais figuras, elas foram impressas com menor espaçamento entre si). Na maioria dessas tentativas, ocorre erros que não ocorreriam quando essa dimensão não foi manipulada. Isso pode ser observado na Tabela 5 ao se comparar as duas atividades em que essa disposição é manipulada com as anteriores em que não há tal manipulação.

Algumas das respostas incorretas de A., também possivelmente ficaram sob controle da disposição espacial das figuras nas fileiras, quando os valores numéricos eram maiores que quatro; diante de três fileiras compostas por sete, oito e nove figuras, A. foi instruída a escolher a fileira que tivesse menos figuras; a criança incorretamente selecionou a fileira composta por nove figuras, as quais foram impressas uma perto da outra, compondo uma fileira curta, diferente da fileira composta por sete figuras e que foram impressas uma longe da outra, compondo uma fileira mais longa.
O participante L. teve um número de acertos relativamente maior nas atividades relacionadas ao conceito de mais ( 22 de 24 tentativas) do que nas atividades relacionadas ao conceito de menos ( 15 de 24 tentativas). A maior parte dos erros relacionados ao conceito de menos ocorreram em tentativas com três estímulos-comparação - apresentados sob a forma de conjuntos ou de fileiras ou de algarismos - o que leva a supor que o aumento de dois para três estímulos-comparação tornou a atividade mais difícil.

Na Tabela 6, os desempenhos de A., L. e S. podem ser observados nas atividades relacionadas ao conceito de maior. Foram testadas 11 relações entre os estímulos: palavra falada "maior" (componente da instrução de cada atividade), conjuntos de figuras, fileiras de figuras, algarismos e o sinal de maior (>) por meio de 33 tentativas. Nessas atividades não foi observado, no desempenho de cada participante, a diminuição do número de acertos relacionado ao aumento dos valores numéricos, identificado na maioria das atividades anteriores.

\section{Tabela 6}

Desempenho dos Participantes A., L. e S. em Atividades das Unidades (indicadas com números) nas quais as Relações entre Estímulos e Respostas Envolvem o Conceito de Maior entre os Estímulos, em Função de Valores Numéricos Empregados: Menores (variando-se entre um e três), Intermediários (entre quatro e seis) e maiores (entre sete e nove). São Indicadas com X Tentativas Corretas

\begin{tabular}{|c|c|c|c|c|c|c|c|c|c|}
\hline \multirow{2}{*}{$\begin{array}{l}\text { Unidade. Relação entre estímulo-modelo - estímulos- } \\
\text { comparação e respostas }\end{array}$} & \multicolumn{3}{|c|}{1 a 3} & \multicolumn{3}{|c|}{4 a 6} & \multicolumn{3}{|c|}{7 a 9} \\
\hline & A & $\mathrm{L}$ & $\mathrm{S}$ & A & $\mathrm{L}$ & $\mathrm{S}$ & A & $\mathrm{L}$ & $\mathrm{S}$ \\
\hline
\end{tabular}

2. Palavra falada "maior" - Escolher, entre dois conjuntos com números diferentes de figuras, o conjunto que tem o maior número de figuras

X $\quad \mathrm{X} \quad \mathrm{X} \quad \mathrm{X}$

2. Palavra falada "maior" - Escolher, entre duas fileiras com $\begin{array}{llll}\text { números diferentes de figuras, a com maior número de figuras, } & \mathrm{X} & \mathrm{X} & \mathrm{X}\end{array}$ com variação na disposição espacial das figuras

2. Palavra falada "maior" - Escolher, entre três conjuntos com números diferentes de figuras, o conjunto que tem o maior número de figuras

2. Palavra falada "maior" - Escolher, entre três fileiras com números diferentes de figuras, a fileira com o maior número, com variação na disposição espacial das figuras

3. Palavra falada "maior" - Escolher, entre dois algarismos diferentes, o algarismo cujo valor numérico é maior

$\begin{array}{llllll}X & X & X & X & X & X\end{array}$

3. Palavra falada "maior" - Escolher, entre três algarismos diferentes, o algarismo cujo valor numérico é maior

$\begin{array}{lllllll}X & X & X & & X & X \\ X & X & & & & & \\ & & & & & & \\ \text { X } & & & X & X & X\end{array}$


3. Palavra falada "maior" e Conjunto de figuras - Escolher, entre três algarismos diferentes, aquele cujo valor numérico é maior do que o número de figuras do conjunto

X $\quad$ X

4. Palavra falada "maior" e Dois conjuntos compostos por números diferentes de figuras - Escolher, entre o sinal de maior e o sinal de menor, o sinal de maior

4. Palavra falada "maior" e Dois algarismos diferentes - Escolher, entre o sinal de maior e o sinal de menor, o sinal de maior

$\mathrm{X} \quad \mathrm{X}$

$\mathrm{X} \quad \mathrm{X} \quad \mathrm{X}$

$\mathrm{X} \quad \mathrm{X}$

4. Palavra falada "maior" e Dois conjuntos com números diferentes de figuras - Escolher, entre o sinal de maior, o sinal de $\mathrm{X}$ igualdade e o sinal de menor, o sinal de maior

4. Palavra falada "maior" e Dois algarismos diferentes - Escolher, X entre o sinal de maior, o sinal de igualdade e o sinal de menor, o sinal de maior

Total de acertos

$\begin{array}{lllll}X & X & X & X & X\end{array}$

$\mathrm{X} \quad \mathrm{X} \quad \mathrm{X}$

$\mathrm{X} \quad \mathrm{X} \quad \mathrm{X}$
A participante A. apresentou um número de acertos relativamente maior em tentativas de valores de um a três (10 em 11), em comparação ao número de respostas corretas observadas em tentativas com valores de quatro a seis e valores de sete a nove (4 e 5 respectivamente). Os participantes L. e S. apresentaram menos acertos nas tentativas em que foram empregados os valores de um a três, em comparação às tentativas nas quais foram usados valores de quatro a seis e valores de sete a nove; porém, foi pequena a diferença no número de acertos entre as tentativas das faixas de valores menores, intermediários e maiores: a diferença variou entre zero e dois acertos.

Na Tabela 7, são descritos os estímulos antecedentes e as respostas de cada atividade que abordou o conceito de menor, assim como o desempenho de cada criança. Nas atividades, foram testadas 11 relações entre os estímulos: palavra falada "menor" (componente da instrução), conjuntos de figuras, fileiras de figuras, algarismos e o sinal de menor $(<)$, por meio de 33 tentativas. A participante A. emitiu mais respostas corretas (sete em 11) em tentativas nas quais valores numéricos de sete a nove foram adotados, em comparação ao número de acertos apresentados em tentativas com valores numéricos inferiores (três e quatro acertos). Nas tentativas em que valores de um a três foram empregados, a participante A. apresentou uma diferença grande de acertos entre atividades relacionadas ao conceito de maior (19 acertos) e atividades relativas ao conceito de menor (14 acertos). O participante L. apresentou mais acertos nas tentativas em que os valores de um a três foram empregados (sete acertos), em comparação ao número de respostas corretas nas tentativas dos valores de quatro a seis e teve diferença de somente um acerto em relação às tentativas dos valores de sete a nove (seis acertos). A participante $\mathrm{S}$. emitiu um número relativamente maior de respostas corretas em tentativas com valores de quatro a seis (seis acertos), comparando-se ao número de acertos em tentativas com os valores de um a três e de sete a nove (um e dois acertos, respectivamente).

Respostas incorretas das crianças em atividades relacionadas ao conceito de maior e conceito de menor podem ter ocorrido em função de uma conjunção de fatores: fraco controle que os estímulos gerados pela própria criança - números resultantes da contagem correta das figuras - exerceram sobre as respostas de escolher um conjunto ou uma fileira; controle exercido por dimensão irrelevante, tal como a disposição espacial de figuras em fileiras (a fileira com maior número de figuras foi impressa de modo que as figuras foram dispostas uma perto da outra, formando uma fileira mais curta, e a fileira com menor número de figuras foi impressa de maneira que as figuras foram dispostas mais longe uma da outra, formando uma fileira mais curta); au- 


\section{Tabela 7}

Desempenho dos Participantes A., L. e S. em Atividades das Unidades (indicadas com números) nas quais as Relações entre Estímulos e Respostas Envolvem o Conceito de Menor entre os Estímulos, em Função de Valores Numéricos Empregados: Menores (variando-se entre um e três), Intermediários (entre quatro e seis) e Maiores (entre sete e nove). São Indicadas com X Tentativas Corretas

Unidade. Relação entre estímulo-modelo - estímulos1 a 3 4 a 6 7 a 9 comparação e respostas

\begin{tabular}{lllllllll} 
& 1 a 3 & & 4 a & & & 7 a 9 \\
\hline A & L & S & A & L & S & A & L \\
X & X & & & X & & X & X
\end{tabular}

2. Palavra falada "menor" - Escolher, entre dois conjuntos com números diferentes de figuras, o conjunto que tem o menor número de figuras

2. Palavra falada "menor" - Escolher, entre duas fileiras com números diferentes de figuras, a com menor número de figuras, com variação na disposição espacial das figuras

2. Palavra falada "menor" - Escolher, entre três conjuntos com números diferentes de figuras, o conjunto que tem o menor número de figuras

2. Palavra falada "menor" - Escolher, entre três fileiras com números diferentes de figuras, a com menor número, com variação na disposição espacial das figuras

3. Palavra falada "menor" - Escolher, entre dois algarismos diferentes, o algarismo cujo valor numérico é menor

3. Palavra falada "menor" - Escolher, entre três algarismos diferentes, o algarismo cujo valor numérico é menor

3. Palavra falada "menor" e Conjunto de figuras - Escolher, entre três algarismos, aquele cujo valor numérico é menor do que o número de figuras do conjunto

4. Palavra falada "menor" e Dois conjuntos compostos por números diferentes de figuras - Escolher, entre o sinal de menor e o sinal de maior, o sinal de menor

4. Palavra falada "menor" e Dois algarismos diferentes Escolher, entre o sinal de menor e o sinal de maior, o sinal de menor

4. Palavra falada "menor" e Dois conjuntos com números diferentes de figuras - Escolher, entre o sinal de menor, o sinal de igualdade e o sinal de maior, o sinal de menor
$\mathrm{X}$

$\mathrm{X} \quad \mathrm{X}$

$\mathrm{X}-\mathrm{X} \quad \mathrm{X}$

$\mathrm{X} \quad \mathrm{X} \quad \mathrm{X} \quad \mathrm{X}$

X $\quad$ X

$\mathrm{X} \quad \mathrm{X} \quad \mathrm{X} \quad \mathrm{X}$

$\mathrm{X}$

$\mathrm{X} \quad \mathrm{X} \quad \mathrm{X} \quad \mathrm{X}$

4. Palavra falada "menor" e Dois algarismos diferentes -

Escolher, entre o sinal de menor, o sinal de igualdade e o sinal de $\quad X \quad X \quad X \quad X$ maior, o sinal de menor

\begin{tabular}{lllllllllll}
\hline Total de acertos & 4 & 7 & 1 & 3 & 4 & 6 & 7 & 6 & 2
\end{tabular}

mento no grau de dificuldade quando se passou de dois estímulos-comparação para três estímulos-comparação; fraco estabelecimento de relações entre palavra falada "igual" e sinal de igualdade, palavra falada "maior" e o sinal de maior, e palavra falada "menor" e sinal de menor.

Na Tabela 8, são apresentadas respostas de A. e S. em atividades de escolha-de-acordo-com- -o-modelo relacionadas ao conceito de sequência crescente e que tiveram números falados e algarismos como estímulos antecedentes. Conforme é possível observar na Tabela 8 , as crianças emitiram, nas três relações testadas, mais respostas corretas nas tentativas em que valores de um a três foram empregados do que nas tentativas em que valores entre sete e nove foram usados. 
Tabela 8

Desempenho das Participantes A. e S em Atividades de Escolha-de-Acordo-com-o-Modelo das Unidades (indicadas com números) nas quais as Relações entre Estímulos e Respostas Envolvem a Sequência Crescente, em Função de Valores Numéricos Empregados: Menores (variando-se entre um e três), Intermediários (entre quatro e seis) e Maiores (entre sete e nove). São Indicadas com X Tentativas Corretas

\begin{tabular}{lcccccc}
\hline Unidade. Relação entre estímulo-modelo - estímulos-comparação & \multicolumn{2}{c}{ 1 a 3 } & 4 a 6 & & 7 a 9 \\
\cline { 2 - 7 } e respostas & A & S & A & S & A & S \\
\hline $\begin{array}{l}\text { 5. Algarismo - Escolher, dentro de uma sequência crescente } \\
\text { de algarismos, o algarismo igual. }\end{array}$ & X & X & X & X & X & X \\
$\begin{array}{l}\text { 5. Número falado - Escolher, dentro de uma sequência crescente de } \\
\text { algarismos, o algarismo correspondente. }\end{array}$ & X & X & X & & & X \\
$\begin{array}{l}\text { 5. Algarismo impresso dentro de sequência crescente - Emitir resposta } \\
\text { textual evocada pelo algarismo. }\end{array}$ & X & X & X & & \\
\hline Total de acertos & 3 & 3 & 3 & 1 & 1 & 1 \\
\hline
\end{tabular}

Atividades de escolha-de-acordo-com-o-modelo relativas ao conceito de sequência decrescente, semelhantes às com o conceito de sequência crescente, foram realizadas apenas pela participante A. A criança apresentou respostas corretas em todas as tentativas da atividade testada tanto para a sequência crescente como para a sequência decrescente que envolveu a identidade física entre algarismos (Algarismo - Escolher, dentro de uma sequência de algarismos, o algarismo igual). A criança somente emitiu respostas incorretas nas tentativas em que foram usados valores de sete a nove das atividades que abordaram a relação entre número falado e algarismo e resposta textual evocada por algarismo (Número falado - Escolher, dentro de uma sequência de algarismos, o algarismo correspondente; e Algarismo impresso dentro de sequência Emitir resposta textual evocada pelo algarismo).

Foram realizadas ainda, com os participantes A. e S., atividades de recitar, escolher e ordenar de um a nove em sequência crescente. Nas três tentativas de cada uma dessas atividades, foram emitidas pelas crianças respostas para cada um dos nove valores, o que difere essas atividades das outras atividades aplicadas durante o estudo. Tanto a participante A. como a participante $\mathrm{S}$. recitaram os números de um a nove corretamente, em todas tentativas.

As crianças também ordenaram, sem erros, os algarismos de 1 a 9 na ordem igual à ordem da sequência apresentada como estímulo-modelo. $\mathrm{O}$ desempenho nessa atividade de resposta construída de identidade diferiu do desempenho observado na atividade de resposta construída arbitrária de ordenar os algarismos em sequência crescente sem ter outra sequência como modelo, atividade em que A. e S. emitiram respostas incorretas.

A participante A. numerou corretamente as cinco primeiras figuras, regularidade essa observada no desempenho de A. em outras atividades: a de escolher o algarismo correspondente a cada um dos nove conjuntos de figuras apresentados em sequência crescente, e a de ordenar os algarismos de 1 a 9 .

A participante A realizou ainda atividades nas quais relações entre estímulos e respostas envolvem o conceito de sequências decrescentes. Ela emitiu mais respostas corretas nas atividades relacionadas à sequência crescente do que naquelas relacionadas à sequência decrescente, resultado que era previsível, uma vez que, em experiências informais e formais, as crianças são primeiramente ensinadas a recitar os números em sequência crescente. De maneira geral, tanto os erros na recitação de números em sequência decrescente como também os erros na ordenação de conjuntos e de algarismos - em sequência crescente e decrescente - se concentraram para os valores superiores a quatro ou cinco. Semelhante concentração de erros, para valores acima de cinco, pode ser observada para a participante S., nas atividades de sequência crescente a que ela foi exposta. 
A dificuldade das crianças em ordenar os nove conjuntos de figuras e os nove algarismos, assim como a dificuldade em ordenar figuras de tamanhos diferentes (na Fase Preliminar), indica a grande complexidade da atividade. Em outros trabalhos, ao invés de o aluno ser solicitado a ordenar de uma só vez nove estímulos (sejam eles figuras, conjuntos ou algarismos), ele deveria ser inicialmente solicitado a ordenar três estímulos; um estímulo novo poderia ser introduzido em um passo posterior para ser ordenado junta- mente com aqueles três estímulos previamente ordenados; e, em cada passo seguinte, um novo estímulo poderia ser introduzido, até que os nove estímulos fossem juntamente ordenados.

As porcentagens de acertos, dos três participantes, nas relações entre estímulos e respostas que envolvem relações entre estímulos de igualdade, mais, menos, maior, menor e sequência crescente, em função de diferentes valores numéricos empregados estão reunidas na Figura 2.
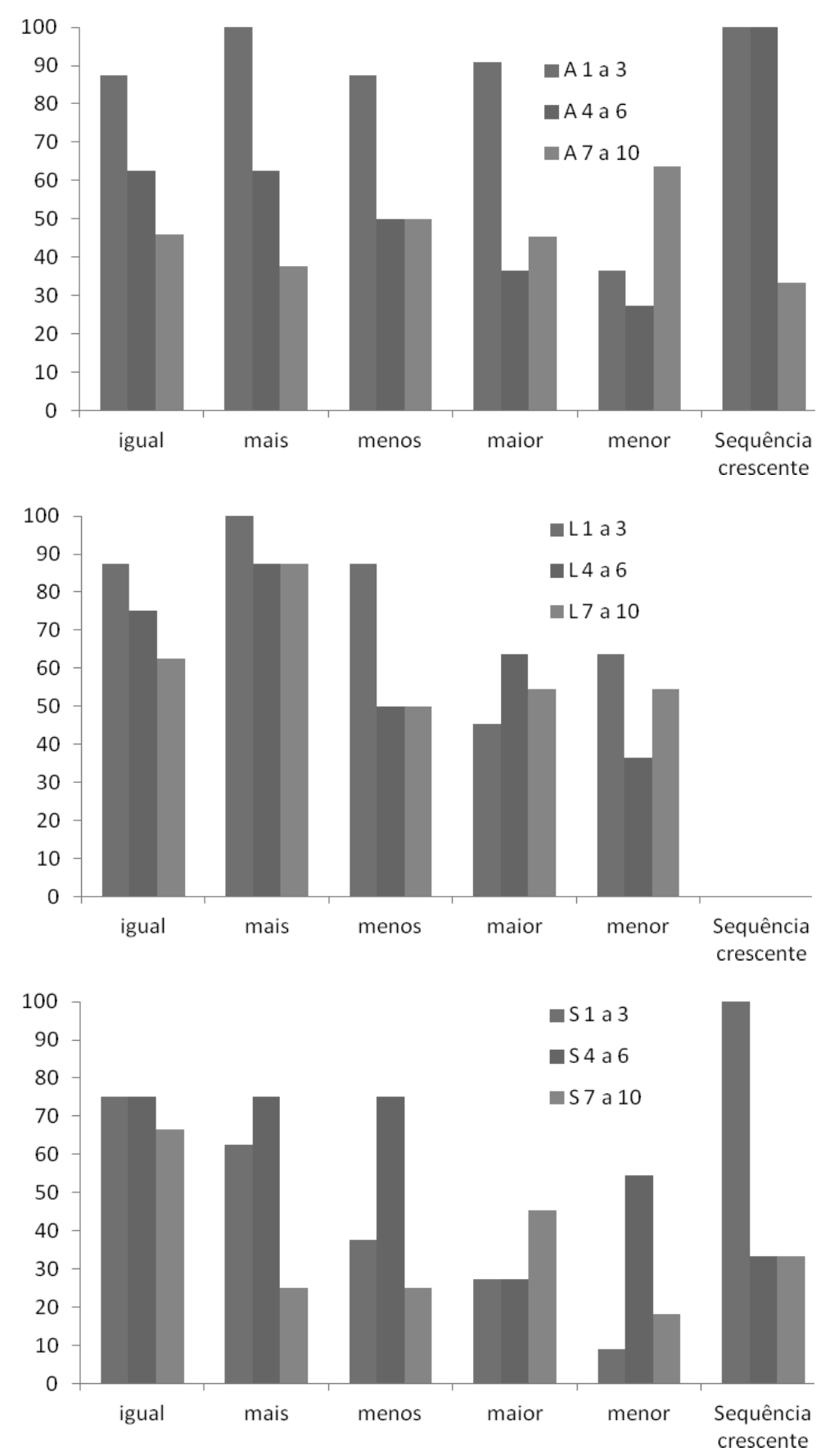

Figura 2. Porcentagem de acertos nas relações estimulos e respostas relativas aos conceitos avaliados dos participantes A, L e S., na fase de comparações numéricas. 
Observando o desempenho dos três participantes nas atividades, é possível dizer que A., L. e $\mathrm{S}$, em geral, emitiram mais respostas corretas nas tentativas em que foram usados valores numéricos menores do que nas tentativas em que foram empregados valores maiores (entre sete $\mathrm{e}$ nove). Os acertos para A. L. em geral diminuem ou se mantém igual com o aumento dos valores numéricos. Nos valores entre 4 e 6 as porcentagens de acerto foram maiores que nos valores 7 a 10 , exceto para as relações maior e menor do participantes A, relação menor para o participante $\mathrm{L}$ e relação maior para o participante $\mathrm{S}$.

Os resultados obtidos neste estudo condizem com as propostas de Resnick et al. (1973) e de Teixeira (2002) de inicialmente serem ensinadas relações entre estímulos e respostas para os valores de um a cinco e, posteriormente, serem introduzidos valores maiores; e, ainda, condiz com a sugestão fornecida por Prado e Carmo (2004), de o professor iniciar o ensino com os valores de um a quatro, passar para os valores cinco e seis (o que representaria um desafio a mais ao aluno por requererem a contagem) e, após o domínio dos valores seis e sete, introduzir os valores oito e nove. A partir dos resultados, é possível indicar que as proposta desses autores podem ser estendidas para outras relações avaliadas neste estudo.

Supostamente, a comparação entre conjuntos compostos por números maiores de figuras, superiores a quatro ou cinco elementos, requer que a criança conte as figuras de cada conjunto. A importância da contagem foi corroborada no estudo conduzido por Monteiro e Medeiros (2002), que ao ensinarem pré-escolares relações entre algarismo e número de elementos, algarismo e palavra impressa, número falado e algarismo, obtiveram melhores resultados com crianças que previamente aprenderam a contar.

$\mathrm{E}$, se a contagem de elementos é fundamental para o estabelecimento de comportamentos matemáticos mais complexos, o professor precisa avaliar e planejar cuidadosamente o ensino da contagem na pré-escola, evitando que seus alunos tenham dificuldades ao ingressarem na primeira série do ensino fundamental (Pra- do, Bonalumi, Bonfim, Ramirez, \& Carvalho, 2006).

Cada atividade aplicada nesse estudo teve três tentativas, sendo que, em uma tentativa, o valor numérico do estímulo foi ou um, ou dois, ou três; em outra tentativa, o valor do estímulo antecedente foi ou quatro, ou cinco, ou seis; e, em outra tentativa, o valor do estímulo antecedente foi ou sete, ou oito, ou nove. Nenhum dos nove valores foi empregado como estímulo antecedente em todas as atividades, uma vez que buscou-se avaliar uma amostra inicial do repertório do aluno de forma a não estender excessivamente a avaliação. Entretanto, no trabalho do professor seria importante que cada um dos nove valores fosse empregado como estímulo antecedente em todas as atividades que compõem a avaliação, de maneira a verificar quais relações comportamentais para cada valor numérico já estão estabelecidas no repertório e quais relações precisam ser ensinadas. Avaliações semelhantes foram conduzidas por Prado (2001) e por Prado e de Rose (1999), utilizando os valores de um a nove, e analisando o desempenho individual de cada aluno em atividades que testaram relações concebidas pelos autores como componentes do conceito de número.

As relações que Prado (2001) e Prado e de Rose (1999) conceberam como componentes do conceito de número foram introduzidas, no presente trabalho, nos conceitos de igualdade (uma vez que diferentes estímulos partilham valor numérico igual) e de sequência crescente (especificamente, as relações de ordenar conjuntos de figuras e algarismos). O domínio da contagem e das relações entre número falado, conjuntos com número igual de elementos, algarismo e respostas de nomear e formar subconjunto parece ser imprescindível para que sejam estabelecidas, no repertório do aluno, as outras relações que envolvem os conceitos de igualdade, mais, menos, maior, menor, sequência crescente e sequência decrescente.

$\mathrm{Na}$ avaliação das relações comportamentais, é importante que o professor considere o controle que dimensões irrelevantes de estímulos podem exercer sobre as respostas do aluno e, por con- 
seguinte, planeje diferentes atividades em que a dimensão relevante - o número - seja mantida e dimensões irrelevantes sejam variadas, de maneira a verificar se, em todas as atividades, as respostas corretas do aluno estão realmente sob controle da dimensão relevante.

\section{Referências}

Araújo, P. M., \& Ferreira, P. R. S. (2008). Ensinando subtração para pessoas com deficiência mental com base em relações de equivalência de estímulos. Psicologia: Teoria e Pesquisa, 24(3), 313-322. Recuperado em http://www.scielo.br/ $\mathrm{pdf} / \mathrm{ptp} / \mathrm{v} 24 \mathrm{n} 3 / \mathrm{v} 24 \mathrm{n} 3 \mathrm{a} 07 . \mathrm{pdf}$

De León, N. P. A. (1998). Aquisição de habilidades básicas de matemática através da formação de equivalência em crianças pré-escolares (Dissertação de mestrado não-publicada, Programa de Pós-Graduação em Educação Especial, Universidade Federal de São Carlos, SP, Brasil).

De Rose, J. C. (1993). Classes de estímulos: Implicações para uma análise comportamental da cognição. Psicologia: Teoria e Pesquisa, 9(2), 283-301.

De Rose, J. C. (2004). Além da resposta correta: Controle de estímulo e o raciocínio do aluno. In M. M. C. Hübner \& M. Marinotti (Eds.), Análise do Comportamento para a Educação: Contribuições recentes (pp. 103-113). Santo André, SP: Esetec.

De Rose, J. C. (2005). Análise comportamental da aprendizagem de leitura e escrita. Revista Brasileira de Análise do Comportamento, 1(1), 2950. Recuperado em http://www.periodicos.ufpa. br/index.php/rebac/article/view/676/965

Gast, D. L., VanBiervliet, A., \& Spradlin, J. E. (1979). Teaching number-word equivalences: A study of transfer. American Journal of Mental Deficiency, 83(5), 524-527.

Green, G. (1993). Stimulus control technology for teaching number-quantity equivalences. In Proceedings of the 1992 Conference of the National Association for Autism (pp. 51-63). Melbourne, Australia: Victoria Autistic Children's and Adults Association.

Kahhale, E. M. S. P. (1993). Comportamento matemático: Formação e ampliação do conceito de quantidade e relações de equivalência (Tese de doutorado não-publicada, Programa de Pós-Graduação em Psicologia Experimental, Universidade de São Paulo, SP, Brasil).

Monteiro, G., \& Medeiros, J. G. (2002). A contagem oral como pré-requisito para a aquisição do conceito de número com crianças pré-escolares. Estudos de Psicologia, 7(1), 73-90. doi:10.1590/ S1413-294X2002000100009. Recuperado em http://www.scielo.br/pdf/epsic/v7n1/10956.pdf

Prado, P. S. T. (2001). Ensinando o conceito de número: Contribuições do paradigma de rede de relações (Tese de doutorado, Universidade de São Paulo, SP, Brasil).

Prado, P. S. T., Bonalumi, G. C., Bonfim, J. C., Ramirez, A. P., \& Carvalho, E. C. P. (2006). Contagem e equiparação de conjuntos: Um estudo correlacional. In S. Zambello de Pinho \& J. R. C. Saglietti (Eds.), Núcleos de ensino (Vol. 3, pp. 348-372). São Paulo, SP: Editora da Universidade Estadual Paulista "Júlio de Mesquita Filho". Recuperado em http://www. unesp.br/prograd/PDFNE2004/artigos/eixo5/ contagem.pdf

Prado, P. S. T., \& Carmo, J. S. (2004). Fundamentos do comportamento matemático: A importância dos pré-requisitos. In M. M. C. Hübner \& M. Marinotti (Eds.), Análise do Comportamento para a Educação: Contribuições recentes (pp. 137-157). Santo André, SP: Esetec.

Prado, P. S. T., \& de Rose, J. C. (1999). Conceito de número: Uma contribuição da análise comportamental da cognição. Psicologia: Teoria e Pesquisa, 15(3), 227-235. doi:10.1590/S010237721999000300006. Recuperado em http:// www.scielo.br/pdf/ptp/v15n3/06.pdf

Resnick, L. B., Wang, M. C., \& Kaplan, J. (1973). Task analysis in curriculum design: A hierarchically sequenced introductory mathematics curriculum. Journal of Applied Behavior Analysis, 6(4), 679-710. doi:10.1901/jaba.1973.6-679. Retrieved from http://www.researchgate.net/ publication/6989999_Task_analysis_in_curriculum_design_a_hierarchically_sequenced_introductory_mathematics_curriculum

Rossit, R. A. S. (2004). Matemática para deficientes mentais: Contribuições do paradigma de equivalência de estímulos para o desenvolvimento e avaliação de um currículo (Tese de doutorado, Programa de Pós-Graduação em Educação Especial, Universidade Federal de São Carlos, SP, 
Brasil). Recuperada em http://www.bdtd.ufscar. br/htdocs/tedeSimplificado//tde_arquivos/9/ TDE-2004-11-27T09:24:25Z-255/Publico/DoutRASR.pdf

Silva, L. C. C. (1999). Análise de uma bateria de teste para o levantamento dos pré-requisitos do comportamento de contar. In J. S. Carmo, L. C. C. Silva, \& R. M. E. Figueiredo (Eds.), Dificuldades de aprendizagem no ensino de leitura, escrita e conceitos matemáticos: Exercícios de Análise do Comportamento (pp. 99-116). Belém, PA: Editora da Universidade da Amazônia.

Teixeira, A. M. S. (2002). Componentes verbais do repertório matemático elementar. In H. J. Guilhardi, M. B. B. P. Madi, P. P. Queiroz, \& M. C.
Scoz (Eds.), Sobre comportamento e cognição: Vol. 9. Contribuições para a construção da teoria do comportamento (pp. 1-12). Santo André, SP: Esetec.

Williams, K. D. (2000). Teaching pre-math skills via stimulus equivalence procedures (Master's thesis, Graduate School Southern Illinois University, Carbondale, IL, USA).

Recebido: 20/06/2012

$1^{a}$ revisão: $17 / 05 / 2014$

Aceite final: 31/07/2014 